\title{
Clinical Application of Genome and Exome Sequencing as a Diagnostic Tool for Pediatric Patients: a Scoping Review of the Literature
}

\author{
Hadley Stevens Smith, MPSA ${ }^{1}$, J. Michael Swint, $\mathrm{PhD}^{2}$, Seema R. Lalani, MD ${ }^{3}$, \\ Jose-Miguel Yamal, $\mathrm{PhD}^{4}$, Marcia C. de Oliveira Otto, $\mathrm{PhD}^{4}$, Stephan Castellanos, BA ${ }^{5}$, \\ Amy Taylor, $\mathrm{MLS}^{6}$, Brendan H. Lee, MD, PhD ${ }^{5}$ and Heidi V. Russell, MD, PhD ${ }^{7}$
}

Purpose: Availability of clinical genomic sequencing (CGS) has generated questions about the value of genome and exome sequencing as a diagnostic tool. Analysis of reported CGS application can inform uptake and direct further research. This scoping literature review aims to synthesize evidence on the clinical and economic impact of CGS.

Methods: PubMed, Embase, and Cochrane were searched for peer-reviewed articles published between 2009 and 2017 on diagnostic CGS for infant and pediatric patients. Articles were classified according to sample size and whether economic evaluation was a primary research objective. Data on patient characteristics, clinical setting, and outcomes were extracted and narratively synthesized.

Results: Of 171 included articles, 131 were case reports, 40 were aggregate analyses, and 4 had a primary economic evaluation aim.
Diagnostic yield was the only consistently reported outcome. Median diagnostic yield in aggregate analyses was $33.2 \%$ but varied by broad clinical categories and test type.

Conclusion: Reported CGS use has rapidly increased and spans diverse clinical settings and patient phenotypes. Economic evaluations support the cost-saving potential of diagnostic CGS. Multidisciplinary implementation research, including more robust outcome measurement and economic evaluation, is needed to demonstrate clinical utility and cost-effectiveness of CGS.

Genetics in Medicine (2019) 21:3-16; https://doi.org/10.1038/s41436018-0024-6

Key Words: genome sequencing; exome sequencing; Review; Clinical implementation; Medical genomics

\section{INTRODUCTION}

Genome-scale next-generation sequencing (NGS) is increasingly applied in clinical settings as a diagnostic tool, indicative of the arrival of an era of medicine with the capacity to provide patient care guided by genetic makeup. ${ }^{1}$ Clinical genomic sequencing (CGS), which includes genome sequencing (GS) and exome sequencing (ES), is unique in the realm of diagnostic tests for two primary reasons. First, results of a single test can both establish a molecular diagnosis and inform tailored medical management (i.e., precision medicine) where applicable. Second, the clinical utility of CGS increases with additional application. Uptake influences diagnostic effectiveness because as more patients are sequenced, detected variants are published in case reports and deposited into public databases, which increases the number of known disease genes and in turn impacts future diagnostic performance of the test.

The interplay of these two qualities is important as genetic research is translated into genomic medicine. Since ES became commercially available as a clinical test in 2011, uptake has been sufficient to generate real world evidence on the ability of CGS to provide a molecular diagnosis and impact patient care. Implementation research is suited to explore the context-dependent and dynamic nature of such evidence. ${ }^{2}$ In an analytical framework of technology translation, synthesis and analysis of reported findings from initial use in the clinic can inform evidence-based practice guidelines and future clinical application. ${ }^{3}$ Both case reports and largerscale studies of institutional implementation are informative at the current stage of evaluation. Case reports demonstrate the breadth of clinical areas in which CGS has been successfully applied. Studies of larger numbers of patients provide aggregate data on diagnostic yield for different forms of the test (e.g., trio versus proband-only, rapid versus nonrapid), and patient subgroups according to phenotype or clinical setting.

Diagnostic potential of CGS has been seen as particularly powerful for infant and pediatric patients because determination of molecular etiology early in life may enable more timely and specific intervention with a better chance of improving

\footnotetext{
${ }^{1}$ Baylor College of Medicine, The University of Texas School of Public Health, Houston, Texas, USA; ${ }^{2}$ The University of Texas School of Public Health, The Center for Clinical Research and Evidence-Based Medicine, The University of Texas McGovern Medical School, Houston, Texas, USA; ${ }^{3}$ Baylor College of Medicine, Baylor Genetics Laboratory, Houston, Texas, USA; ${ }^{4}$ The University of Texas School of Public Health, Houston, Texas, USA; ${ }^{5}$ Baylor College of Medicine, Houston, Texas, USA; ${ }^{6}$ Texas Medical Center Library, Houston, Texas, USA; ${ }^{7}$ Texas Children's Hospital, Baylor College of Medicine, Houston, Texas, USA. Correspondence: Brendan H. Lee (Blee@bcm.edu)
} 
outcomes. ${ }^{4,5}$ Infants who are challenging to diagnose by other modalities because of incomplete, atypical, or blended phenotypes stand to benefit from the multiplex nature of CGS because it does not rely on clinical suspicion of the particular gene implicated. Avoidance of sequential singlegene or gene panel testing can save time, which is valuable because time to diagnosis can impact the availability or effectiveness of clinical intervention. ${ }^{6}$

Establishment of clinical utility of CGS is a primary concern for clinical implementation and the interdependent development of health-care payer policy. Careful evaluations of CGS utilization can inform optimal integration of genome-wide sequencing into diagnostic testing algorithms-where and how to best incorporate CGS into the diagnostic workup for which patients. This involves determining how CGS fits into the landscape of diagnostic decision-making that includes choices between forms of genetic investigation, including targeted genetic tests such as single-gene and gene panel tests, complementary tests such as microarrays and copy-number analysis, and CGS, ${ }^{7}$ which may be performed in addition to or in place of other nongenetic investigations. Although sequencing has typically been recommended for patients with nonspecific clinical features that may be associated with numerous underlying causes (even those that are not yet well established), ${ }^{7}, 8$ it may be possible to more precisely define types of patients who are the best candidates. Development of such guidelines requires assessment of patients' clinical characteristics and effects of CGS on medical management to determine the types of patients most likely to benefit from CGS and its appropriate position in the sequence of diagnostics.

Value assessment is an important component consistent with precision medicine's goal of choosing the right diagnostic test for the right patient at the right time, especially as costly new diagnostics become available." 10 Effectiveness data generated through clinical application studies are required for translational research and are an essential input in economic evaluations to determine the value of the test. ${ }^{3,}{ }^{11}$ While numerous methodological challenges exist for economic evaluations of genomic sequencing tests, ${ }^{12}$ measurement of patient health outcomes is perhaps the largest. Difficulty of outcome measurement is not unique to CGS. It exists across all genetic medicine applications, including targeted and disease-specific genetic tests, and contributes to the lack of robust economic evidence on these applications. ${ }^{13}$ While diagnostic yield is an important outcome, it is only an intermediate measure. More complete assessment of clinical utility would include measures of patients' ultimate health outcome following clinical care provided in light of CGS results. ${ }^{14,}{ }^{15}$ Determination of CGS's value for any specific clinically defined group of patients is further complicated by statistical uncertainty about outcomes (including diagnostic yield) due to small sample sizes, which can obstruct economic model development. ${ }^{16}$

An understanding of how CGS has been applied in practice, its effects on physician decision-making and clinical care, and how outcomes have been reported is a necessary precursor to full economic evaluation. Technical and cost aspects of NGS compared with the gold standard dideoxy method have been explored. ${ }^{17}$ In contrast, evidence on patient outcomes following CGS application has not yet been systematically summarized, which this review seeks to address.

The aim of this scoping review is to provide an overview of published peer-reviewed articles on the application of CGS for diagnostic purposes in infant and pediatric patients. The research questions are (1) what does the literature say about how diagnostic genome-scale sequencing has been applied in clinical settings for infant and pediatric patients; (2) how have results of these applications been reported; and (3) what was the clinical or economic impact? From studies that report aggregate-level analyses, information on institutional features, patient population, reported outcome categories, and impact on those outcomes is summarized. From case reports, disease areas and the genetic spectrum in which diagnostic CGS has been applied are synthesized. For studies that aim to estimate the economic impact of CGS, key findings are outlined and the quality of economic evidence reporting is assessed. This review provides an overview of the landscape of CGS since 2009, when proof-of-concept for diagnostic ES was shown. ${ }^{18,}$ 19

\section{MATERIALS AND METHODS}

\section{Methods}

Scoping reviews are intended to provide an overview of the nature of literature on a topic via structured searches and identify gaps in knowledge. Fewer restrictions for inclusion are placed on patient population, intervention, outcome, and study design than in systematic reviews. This review was conducted according to the Preferred Reporting Items for Systematic Reviews and Meta-Analyses (PRISMA) guidelines, ${ }^{20}$ adapted for use in a scoping review as appropriate. CGS is defined to include GS and ES. Sequencing may have been performed for the proband (i.e., patient) only or alongside parents or other family members (duo or trio), in a nonrapid or a rapid manner with reduced turnaround time. Sequencing was considered clinical rather than research for the purpose of this review if the report's stated goal was to make a diagnosis or otherwise impact medical management of the patient(s). In contrast, if the objective was gene discovery or disease mechanism elucidation, the sequencing was considered research.

A search strategy was designed with the assistance of a librarian from the Texas Medical Center library. PubMed, Embase, and Cochrane Library were searched. The PubMed search included the following Medical Subject Headings $(\mathrm{MeSH})$ terms: Genome; Exome; Sequence Analysis, DNA; Adolescent; Child; Infant; Diagnostic Techniques and Procedures; Clinical Decision-Making; Diagnosis, Differential. Items identified through database searches were imported into the web application Rayyan (Doha, Qatar) for title and abstract screening. ${ }^{21}$ Full search strategies are available online as Supplementary Materials and Methods. Two independent 
reviewers (HSS and SC) screened the title and abstract of each record, and conflicts were resolved through consensus. Citations selected for full-text review were imported into EndNote (Clarivate Analytics, Boston, MA), and full-text articles were obtained. A full-text review form was completed for each article to determine whether inclusion/exclusion criteria were met. One author (HSS) reviewed each full-text article, and a second reviewer (SC) reviewed a randomly selected $10 \%$ of the full-text articles.

Articles that met the following predetermined criteria were included: (1) peer-reviewed original research article; (2) published between January 2009 and June 2017 (with an updated search performed in November 2017); (3) proband (if a case report) or the majority of probands (if more than 5 probands in study) less than 19 years of age at the time of sequencing; (4) described/evaluated the clinical application of a CGS for diagnostic purposes. Studies of patients who had a clinical diagnosis of a condition with known genetic heterogeneity, and thereby not determined to have a "specific" diagnosis, were included. Studies of patients enrolled in a research protocol performing CGS for a clinical purpose were included regardless of how costs of sequencing were covered, as the aim of sequencing was considered more important than the funding arrangement. No restrictions were placed on study design; clinical reports (individual cases and case series), intervention studies (any methodology), and economic evaluations (any methodology) were included.

Publications with a primary aim of genetic research were excluded as were publications on population-based screening, tumor genotyping, mitochondrial genome sequencing only (without the nuclear genome), pharmacogenetic testing, disease carrier testing, prenatal genetic testing, and targeted exome sequencing (e.g., "clinical exome" or "Mendeliome") panels of thousands genes known to be associated with singlegene disorders. While targeted exomes may be considered more similar to a whole exome than targeted panel, multiple permutations of such tests exist. Because there is inconsistency in covered genes, publications on targeted tests were excluded for comparability of results and feasibility of this review. Reports on patients who were sequenced postmortem and those that indicated the initiation of sequencing but not results were also excluded.

Because this scoping review included articles that employed multiple methodologies and studied diverse patient populations, results across studies were summarized and narratively described rather than combined statistically in a meta-analysis. Descriptive statistics were calculated on the number of articles on each type of CGS, characteristics of patients and institutions, clinical scenarios, and reported outcome measures. Discussion of costs and economic evidence was also summarized. The Consolidated Health Economic Evaluation Reporting Standards (CHEERS) checklist was used to assess the quality of reporting in articles with an economic evaluation focus. ${ }^{22}$ Two authors (HSS and HVR) assessed each article independently and arrived at a consensus score.

\section{Data collection process}

We developed and pilot tested a data extraction form, and then created two refined versions based on the two types of analyses and reporting encountered. For the purpose of collecting and presenting results in this review, studies of five or fewer patients were considered "case reports" and studies of more than five patients were considered "aggregate analyses." The cutoff number of five was determined based on differences in article structure and information presentation according to the number of patients included. Thus, the data collection form used for each type of study reflected the way in which facts were reported.

Data items selected for abstraction from articles were broadly based on parameters recommended for assessment in evaluation of genetic tests. ${ }^{23}$ The data collection form for aggregate analyses included the following items: study objective, country, type of CGS, comparator, clinical setting, study design, outcome measures, study population, inclusion criteria, exclusion criteria, average age at test, percent of probands younger than 19 years of age, percent of probands who were male, diagnostic laboratory, sequencing platform, whether a duo and/or trio approach was used, turnaround time, molecular diagnostic yield, number of probands with a change in medical management, discussion of insurance coverage, discussion of costs or cost-effectiveness, and average cost to diagnosis or cost of potentially replaced tests. For case reports, the above information was collected on the individual level as well as the gene implicated and diagnosis. For economic studies, the perspective of the analysis, cost data source, and incremental cost per outcome measure were recorded. One author (HSS) abstracted data from all included studies into a spreadsheet. Analysis was performed with Stata IC 13 (College Station, TX).

\section{RESULTS}

\section{Study selection}

The study selection process is summarized as a PRISMA flow diagram in Fig. 1. Database searches and a hand search yielded 3039 records after duplicates were removed. After review of abstracts, 359 records were selected for full-text review. Following full-text review and resolution of discrepancies by consensus, 135 articles were included and 224 articles were excluded. The inter-rater reliability was high (Cohen's kappa $=0.81$ ) for the $10 \%$ of articles receiving a fulltext review by two investigators, suggesting good agreement on inclusion/exclusion decisions and unbiased selection of articles for inclusion in this review. The search was updated in November 2017, and an additional 36 articles were included.

\section{Study characteristics}

Of the 171 total included articles, 131 (76\%) were case reports $^{19,24-153}$ and 40 (24\%) were aggregate analyses ${ }^{5,6,154-}$ 191. Four studies had a primary objective of economic evaluation and also reported primary effectiveness data ${ }^{153}$, ${ }^{189-191}$. The number of included articles increased by publication year. One article each year was included from 




Fig. 1 Preferred Reporting Items for Systematic Reviews and MetaAnalyses (PRISMA) flow diagram of study selection

2009-2011, 2 from 2012, 7 from 2013, 24 from 2014, 29 from 2015, 48 from 2016, and 58 from 2017. Most studies were conducted in the United States (71) and the European Union (28), followed by Japan (14), Canada (12), China (7), Australia (6), and Korea (5). The first author (or co-first author) listed had a clinical or commercial genetics affiliation for 97 (57\%) of articles. Of 24 items on the CHEERS checklist recommended for reporting, the economic evaluation articles reported 7, 14, 18 , and 17 items.

\section{Syntheses of results}

ES was used in 93\% (159/171) of articles, GS in 6\% (10/171), and a combination of ES and GS in 1\% (2/171). Of the 98 studies that reported the sequencing platform used, $88 \%$ $(86 / 98)$ were Illumina, 6\% (6/98) were Life Technologies, and $3 \%$ (3/98) were Thermo Fisher. The majority (22/40) of aggregate analyses reported sequence analysis of proband-parent trios for at least some cases, 5 of which also reported a duo of the proband and mother (or another firstdegree relative) in some cases. Turnaround time from test order to result return was reported in $25 \%$ (10/40) of aggregate analyses and only 2 case reports. The commercial $\mathrm{lab}(\mathrm{s})$ in which sequence analysis was performed was stated in 19 aggregate analyses and 24 case reports, while 16 aggregate analyses and 87 case reports stated that analysis was performed in-house (some of which were College of
American Pathologists-accredited and Clinical Laboratory Improvement Amendments-certified environments).

The 40 aggregate analyses included an average of 225 patients (median $=79$; range: 6-2,000). Results from the 37 aggregate analyses that did not have a primary aim of economic analysis are summarized in Table 1. Clinical setting and patient population varied widely. Clinical settings included genetics referral centers and hospital specialty clinics (Genetics, Neurology, Epilepsy, Developmental, Dermatology, Mitochondrial Disorders, Hemophilia Treatment), pediatrics departments, and intensive care units. The most common setting was Genetics/Individualized Medicine/Developmental Clinic (12 articles), followed by nonspecific children's hospital/university medical center clinic (9 articles) and Pediatric Neurology/Epilepsy/Intellectual Disability Clinic (6 articles). Clinical laboratory (4 articles) and neonatal/pediatric intensive care unit (3 articles) were also reported settings. Most large sample studies (33/37) were retrospective medical record reviews to form a case series (12 of which were sequential) of patients that met specific inclusion criteria for CGS to be performed. All studies that used data from diagnostic laboratories reported information for consecutively obtained samples.

Phenotypic characteristics were used to delineate the types of patients included in each study. All patients lacked a molecular diagnosis at the time CGS was performed by virtue of the inclusion criteria for this review. Phenotype categories were either determined by the study authors, such as organ system affected, severity of disease, or broad phenotypic class (18 articles), or according to Human Phenotype Ontology (HPO) terms (5 articles). Although the specific category definition varied by study, neurologic phenotypes including intellectual disability (ID)/developmental delay (DD) were a commonly reported phenotypic group (22/37 articles). Diagnostic yield for neurologic phenotypes is presented in Table S1.

Each aggregate analysis reported diagnostic yield, and it was the only consistently reported outcome measure. Where defined, diagnostic criteria were consistent with American College of Medical Genetics and Genomics (ACMG) guidelines. ${ }^{192}$ Patients were considered diagnosed if pathogenic or likely pathogenic variant was detected in a disease gene related to phenotype. Diagnostic yield varied by patient population and type of test. Trio sequencing had a higher yield than proband-only when the two were compared (Table 1). Overall diagnostic yield ranged from 8.4 to $100 \%$, with a median of $33.2 \%$. Other than 3 studies that reported $100 \%$ yield, the highest yield was $68.3 \% .{ }^{178}$ Beyond diagnostic yield, other health outcome measures of the downstream effect of sequencing on medical management were listed ${ }^{5,6}$, $165,173-175,178,180,182$ or presented in a table $154,159,172$ in $30 \%$ of large sample studies. Of the 12 studies that measured them, 8 studies $5,6,172-175,178,182$ provided a definition of outcomes, including providing specific examples of the types of care changes included in each category. 

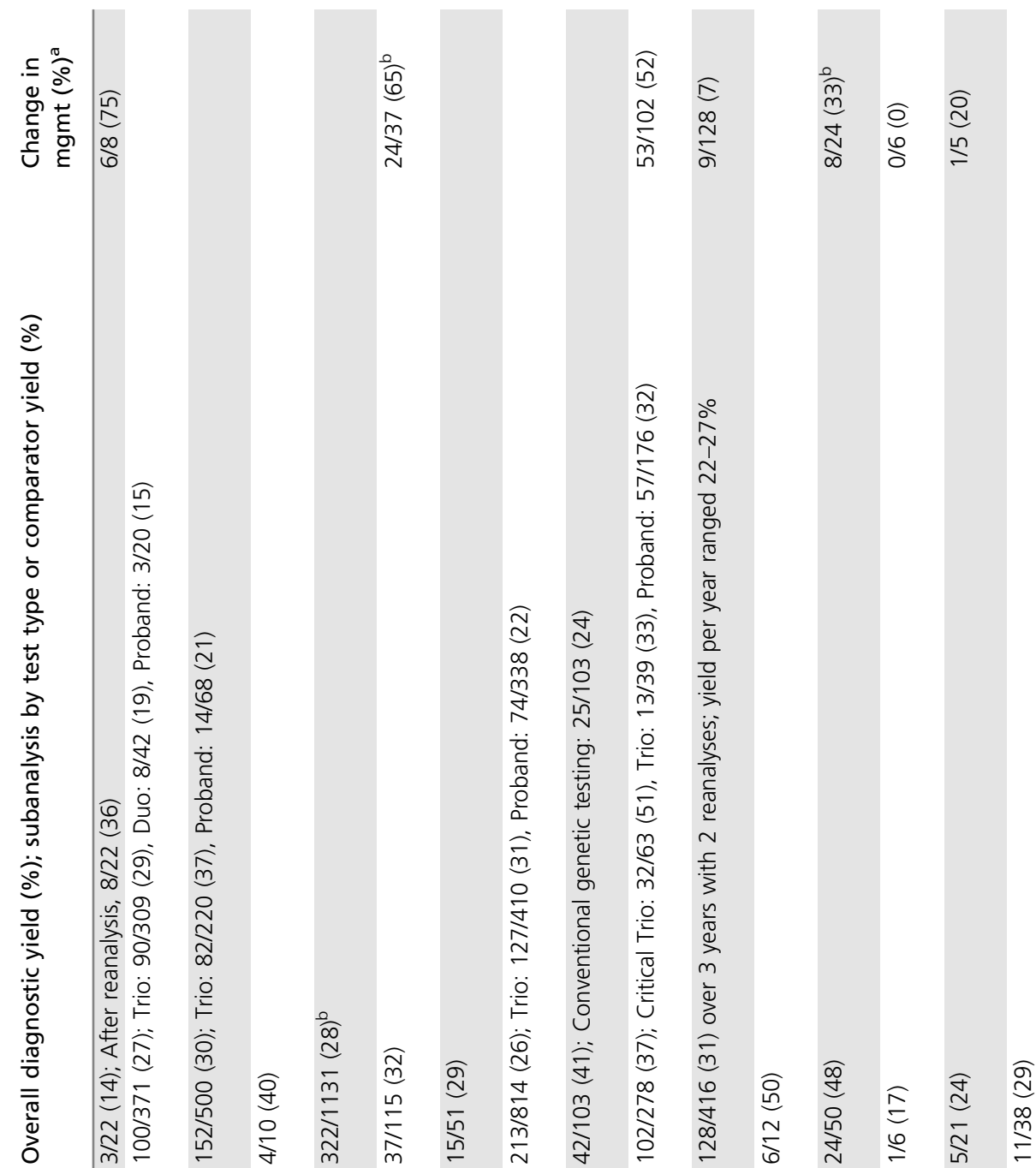

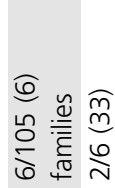

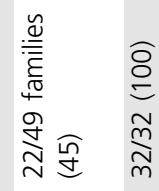
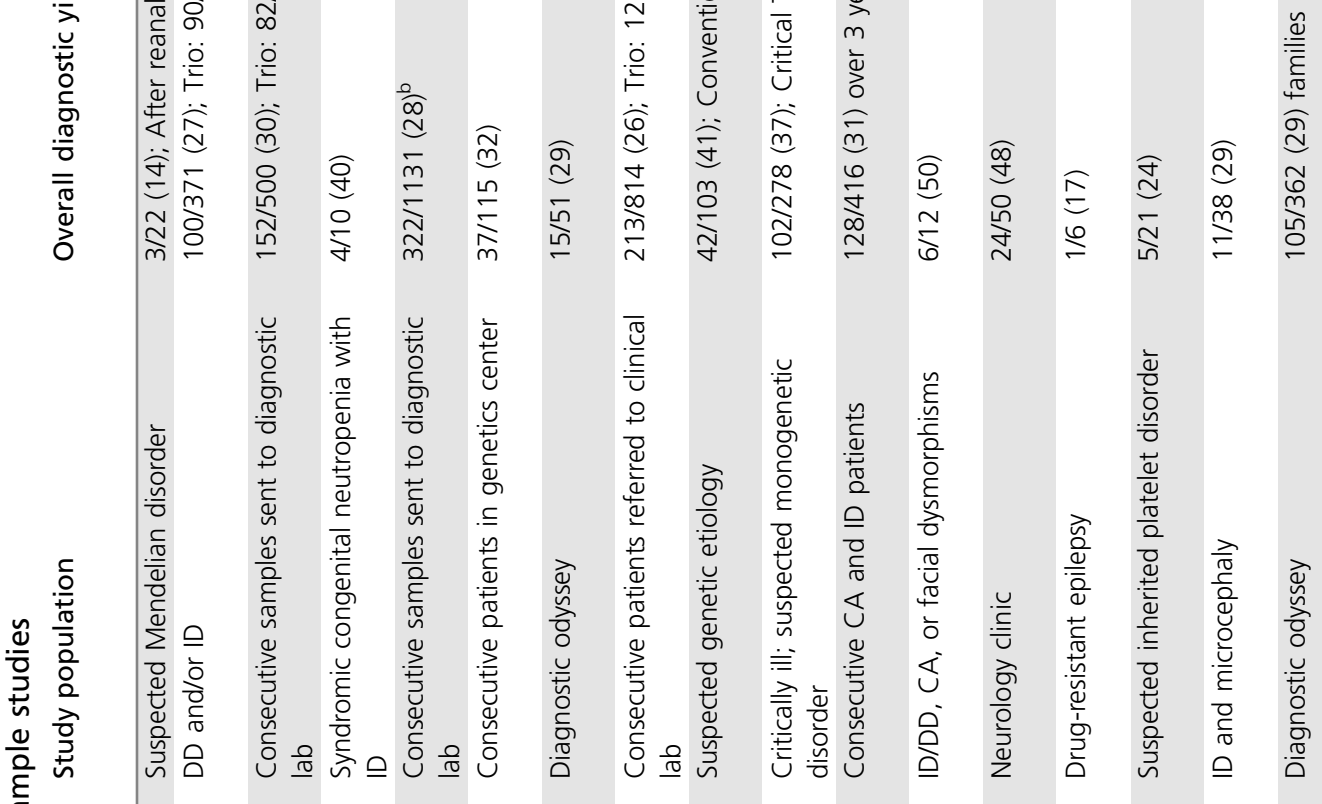

ชั่

응

3

离

กิ

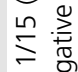

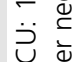

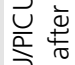

岂芯

它

竞出

岁 $\frac{a}{4}$

毒离

苞



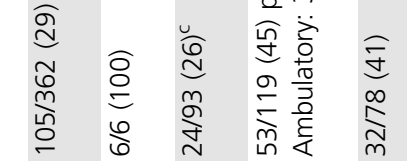

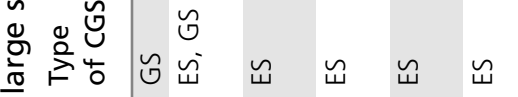



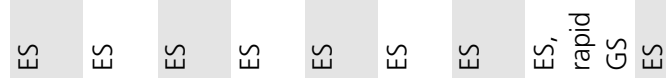

प

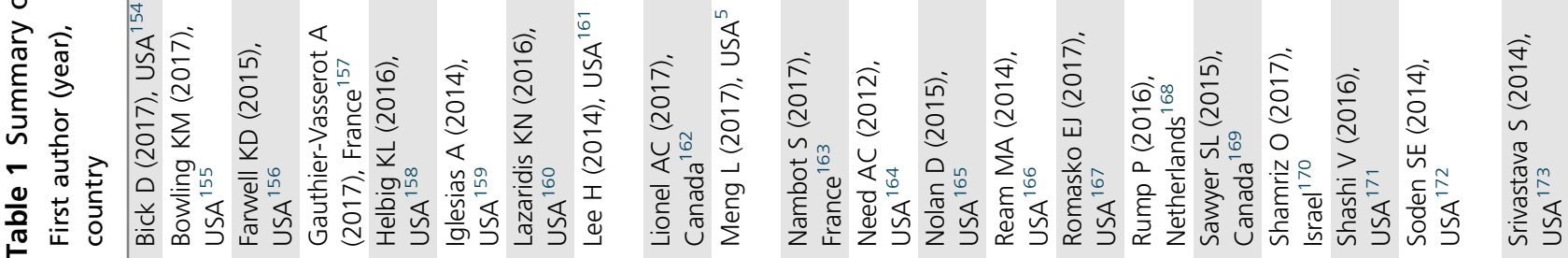







Table 2 Summary of findings in economic evaluation articles

$\begin{array}{llll}\begin{array}{l}\text { First author (year) } \\ \text { country/perspective }\end{array} & \begin{array}{l}\text { Type of economic } \\ \text { evaluation; type of CGS; }\end{array} & \begin{array}{l}\text { Clinical setting; } \\ \text { sample size }\end{array} & \begin{array}{l}\text { Cost of potentially replaced tests / incremental cost per } \\ \text { additional Dx by CGS (in USD) }\end{array}\end{array}$
comparator

\begin{tabular}{|c|c|c|c|}
\hline $\begin{array}{l}\text { Joshi }(2016)^{153} \text { USA / } \\
\text { hospital (not stated) }\end{array}$ & $\begin{array}{l}\text { Descriptive; trio ES; } \\
\text { standard diagnostics }\end{array}$ & $\begin{array}{l}\text { Epilepsy center; } n=4 \\
\text { (including } 2 \text { siblings) }\end{array}$ & $\begin{array}{l}\text { Total charges for standard diagnostics range } \$ 9,015-\$ 35,483 \text {; charge } \\
\text { for trio ES } \$ 6,100 \text { / not calculated }\end{array}$ \\
\hline $\begin{array}{l}\text { Monroe }(2016)^{189} \\
\text { Netherlands / hospital } \\
\text { system }\end{array}$ & $\begin{array}{l}\text { Scenario analysis; trio ES; } \\
\text { standard diagnostics }\end{array}$ & $\begin{array}{l}\text { Specialty center for } \\
\text { intellectual disability; } n \\
=17\end{array}$ & $\begin{array}{l}\text { Average diagnostic odyssey } 6.6 \text { years; average cost of traditional } \\
\text { diagnostic pathway: } \$ 16,409 \text {. For patients who receive Dx, ES to } \\
\text { replace genetic tests would save } \$ 4,986 \text { and to replace metabolic } \\
\text { tests would save } \$ 2,553 \text {, on average. For patients who did not receive } \\
\text { Dx, ES to replace genetic tests would save } \$ 5,669 \text { on average. / not } \\
\text { calculated }\end{array}$ \\
\hline $\begin{array}{l}\text { Stark }(2017)^{190} \text { Australia } \\
\text { / hospital system }\end{array}$ & $\begin{array}{l}\text { CEA; proband ES; standard } \\
\text { diagnostics }\end{array}$ & $\begin{array}{l}\text { NICU, PICU, other } \\
\text { inpatient, and } \\
\text { outpatient; } n=40\end{array}$ & $\begin{array}{l}\text { Avg. cost per Dx, traditional diagnostics: } \$ 21,099, \mathrm{ES}: \$ 3,937 \text { / ES as a } \\
\text { first-tier diagnostic test: savings of } \$ 1,702 ; \mathrm{ES} \text { to replace some } \\
\text { diagnostic tests: } \$ 2,045 \text {; ES after all other diagnostic tests: } \$ 6,327\end{array}$ \\
\hline $\begin{array}{l}\text { Tan }(2017)^{191} \text { Australia / } \\
\text { health care system (not } \\
\text { stated) }\end{array}$ & $\begin{array}{l}\text { CEA; proband ES; standard } \\
\text { diagnostics }\end{array}$ & $\begin{array}{l}\text { Ambulatory outpatient } \\
\text { clinics; } n=44\end{array}$ & $\begin{array}{l}\text { Avg. diagnostic odyssey } 6 \text { years, } 19 \text { tests, cost of } \$ 7,509 \text {. Cost per } \\
\text { patient of ES at initial genetics appointment } \$ 3,933 \text {. / ES at initial } \\
\text { tertiary clinical presentation: savings of } \$ 6,840 \text {; ES at initial genetics } \\
\text { consult: savings of } \$ 4,143 \text {; ES after standard diagnostics: } \$ 4,371\end{array}$ \\
\hline
\end{tabular}

CGS clinical genomic sequencing, Dx diagnosis, ES exome sequencing, CEA cost-effectiveness analysis, NICU neonatal intensive care unit, PICU pediatric intensive care unit

${ }^{a}$ All costs reported.

Aggregate analyses typically included a summary and discussion of molecular findings, and study authors chose clinically interesting examples to highlight. By nature of the report type, molecular findings dominated the discussion of outcomes in case reports. Table S2 presents implicated genes and the associated diagnoses made in case study patients. Among the case studies, 68\% (89/131) reported a diagnostic finding, $19 \%(25 / 131)$ reported a variant considered by the authors to be the most likely candidate for the patient's clinical presentation, and 9\% (11/131) reported a finding that prompted candidate gene association studies. Nondiagnostic findings accompanied by a description of the clinical presentation were reported in $5 \%(6 / 131)$ of case studies. An expansion of the genetic spectrum or clinical phenotype associated with a particular condition was reported in $45 \%$ (59/131) case studies.

Overall, 46\% (78/171) of articles discussed implications of CGS results on the medical management of patients. Impact on clinical care was more frequently discussed in aggregate analyses $(53 \%, 21 / 40)$ than in case reports $(44 \%, 57 / 131)$. Likewise, a discussion of economic impact of CGS on the diagnostic workup was more frequently included in larger studies $(70 \%, 28 / 40)$ than case reports $(15 \%, 19 / 131)$.

Even among the 37 aggregate analyses that did not have a primary objective of economic evaluation, 23 referred to the economic impact of CGS on the diagnostic workup. Several articles specifically stated the need for economic evaluation of such testing ( 5 articles), 5, 6, 161, 174, 185 highlighted that CGS may shorten the time and cost involved in the diagnostic odyssey or sequential single-gene testing (6 articles), 5, 156, 159,
$162,168,170$ or provided an illustrative example or summary statistics on the number or cost of negative diagnostic tests

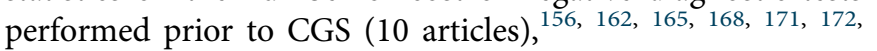
$175,182,183,185$ which could have been averted if CGS had been utilized as a first-line test. Table S3 summarizes findings from articles that included quantitative results related to economic impact of CGS but that did not have a primary economic evaluation objective. Only 5 of 37 studies included a comparison group, which was standard diagnostic investigation. $^{6,162,174,175,183}$ Insurance coverage of CGS was discussed in 8 large studies and 2 case reports. No formal health state, quality of life, utility values, or specific instruments to measure such outcomes were reported.

Results from economic evaluation studies are presented in Table 2. Each analyzed single-study effectiveness data reported in the same publication. In general, the results suggest that ES can be cost-saving when performed as a firsttier diagnostic test and thus replace serial performance of single-gene, gene panel, and other tests. The incremental costeffectiveness ratio may be considered within acceptable limits even if CGS is employed at later points in the diagnostic trajectory. For example, one prospective analysis in which standard diagnostics were performed in parallel with ES found that first-tier ES was associated with an incremental cost savings of US $\$ 1702$ per additional diagnosis, and when ES was performed after standard diagnostics, the incremental cost per additional diagnosis was US $\$ 6327 .{ }^{190}$ Another study estimated incremental savings of US $\$ 6840$ per diagnosis when ES was performed at the initial tertiary clinical visit and incremental cost of US $\$ 4371$ when ES was used after 
standard diagnostic investigations. ${ }^{191}$ These results underline the role of timing and number of other nondiagnostic investigations performed in whether incremental diagnoses via ES lead to savings or come at an additional cost.

\section{DISCUSSION}

In this examination of the published reports of CGS in the pediatric clinical setting, authors of included studies convey enthusiasm about the availability of sequencing technology in the clinic and its potential value as a diagnostic tool. Investigators highlight instances of success in particularly meaningful or puzzling clinical cases. Overall, the results show diagnostic CGS's broad application across clinical settings, increased uptake since commercial availability as measured by the number of publications each year, and high success rates for identification of molecular cause of disease (Table 1). Proliferation of publications appears to reflect diffusion of this diagnostic technology across geographic areas and clinical specialties. Findings of economic evaluations suggest that the multiplex nature of CGS is important for generating value because CGS is capable of replacing other diagnostic tools. However, even if other nondiagnostic investigations are performed prior to CGS, the cost to diagnose an additional patient may still look favorable to decision makers.

Reviewed publications are predominantly retrospective case reports or series across diverse clinical presentations. Among aggregate analyses, $85 \%$ employed a retrospective design. Reports to date can largely be classified as descriptive, although quantitative analysis has improved with time and sample size. While there is work to be done to improve the analytical rigor of analyses, particularly in terms of outcome measurement and economic evaluation, this is to be expected in the assessment of a test with paradigm-shifting diagnostic capability. Best practices should be established for measurement and reporting of outcomes subsequent to sequencing. Standardization would allow more robust analyses to demonstrate clinical utility and cost-effectiveness of CGS. This review suggests multiple candidate categories of outcomes that could be quantified. For example, it may be possible to measure major procedures, imaging studies, or pharmacological intervention averted or initiated as a consequence of GCS results. A framework of standardized category definitions, including specification of procedures and imaging studies considered, and means by which changes are assessed would benefit future research.

Diagnostic yield is the most commonly reported outcome and also the most feasible and straightforward to capture. Results across studies suggest that patient-parent trio sequencing has a higher diagnostic yield than sequencing the proband only (Table 1). Investigators have begun to look at the downstream consequences on patient care; however, categories of clinical impact are not consistently defined or measured. Reported medical management outcomes fall into the following broadly defined categories: surveillance and testing, change in prognosis/impression, subspecialty consult, time to diagnosis, pharmacological intervention, procedure change, imaging change, diet change, palliative care initiation, facility transfer, clinical trial education, family planning, familial genetic testing initiation, genetic counseling, end of diagnostic workup, psychological, and personal/social. Specific wording of outcome categories was not consistent across studies, and details on how assessments were made were rarely provided. Lack of standardization makes comparison across articles difficult. The discussion of care impact in reviewed articles largely centered on a selected few illustrative cases detailed by study authors.

Follow-up time presents another impediment to outcome measurement. It may not be feasible to ascertain all effects of CGS within the study timeframe. The follow-up period in reported studies was not sufficient to measure potential impacts over the course of the patient's lifetime such as access to school and social programs, disease surveillance, or reproductive decision-making of the proband. Widespread effects of CGS may extend many years after sequencing and to multiple members of the proband's family.

The retrospective nature of the majority of evaluations may introduce selection bias due to preferential reporting and patient inclusion criteria. For each article included in this review, results are specific to the particular clinical population studied. The majority of aggregate analyses employed specific inclusion criteria, sometimes determined by a clinical approval process for CGS specified by the institution. For example, patients may have been required to have already undergone a negative diagnostic workup or meet broadly defined clinical criteria, such as ID/DD, to be eligible for CGS. If clinicians selectively include patients whom they have determined CGS would be most likely to yield a diagnosis, the patient sample will not reflect the general patient population. However, the findings will reflect clinical practice and interpretation of results in light of the inclusion criteria may be informative for clinical or institutional policy-making.

There is a risk of publication bias across studies, particularly for case reports and small case series. It is more likely that instances in which CGS was successful in determining a diagnosis for the patient will be published in a case report. Nevertheless, looking across the clinical spectrum where CGS has been successfully applied can indicate the scope of sequencing as a diagnostic tool. It is possible that some patients reported in case studies may also be included in the cohort of patients reported by the treating institution, where both types of publications exist.

Absence of uniformity in outcome categories and measurement across studies may lead to ascertainment bias, or systematic error based on how a particular researcher defines and records a change in medical management. Similarly, inconsistent methods for costs measurement and medical record data abstraction may impact results of studies that assess costs or the number of previous diagnostic tests performed for each patient. Degree of transparent reporting on cost collection and handling can reveal potential sources of bias, such as how missing data, statistical uncertainty, and 
currency conversion and indexing were handled. One indicator of this is the quality of reporting as measured by number of items on CHEERS checklist described in the text, which are intended to inform readers about important aspects of how the analysis was conducted. For studies that include an economic analysis, the level of reporting of economic evidence was low, as approximately half of recommended items on the CHEERS checklist were reported on average. Inconsistency impedes comparison across published studies and makes it difficult to draw conclusions. For example, the percentage of patients for whom CGS results affected medical management cannot be directly compared across studies because it depends upon the types of clinical changes considered and reported in each specific article. At the outcome level, this review is limited by differences in how medical management change is defined by the authors of each study.

Authors of reviewed studies note that the cost-effectiveness of CGS deserves further and more rigorous study and that economic evaluations are an important component of translation to the clinic (Table S3). Discussion of insurance coverage or economics may not have been considered relevant by authors if sequencing was performed under a research protocol. Very few studies have performed a thorough assessment of costs in more than a few example patients. More robust economic evaluation of CGS is needed to quantify the cost effectiveness of testing and to guide reimbursement policy. Of the 4 articles with a primary economic evaluation aim, each limited the cost comparison to the diagnostic odyssey. This may be because outcomes are not clearly defined or because asking what it costs to determine a diagnosis is the most appropriate question at the moment. However, there are numerous cost-related questions that should be explored in future research, such as the cost consequences of earlier diagnosis that may lead to earlier intervention or the decision to not perform medical interventions.

Database searches for this review were limited to PubMed, Embase, and Cochrane. It is possible that additional publications exist outside this search. However, it would be unlikely that relevant studies would not be indexed, and hand searches of other resources supplemented the database searches. This review is limited to articles published in the English language. Inconsistent terminology is a hindrance to systematic searching. ES applied as a clinical diagnostic tool is sometimes abbreviated clinical exome sequencing (CES) or diagnostic exome sequencing (DES). However, CES is also used to refer to targeted exome sequencing of known disease genes, rather than the entire exome. It was necessary to read details of how the analysis was performed to determine whether it covered the whole exome or only a portion. Additionally, the terms "proband-only" and "singleton" are used interchangeably to refer to sequencing only the patient, and tests with expedited turnaround time are referred to as both "rapid" and "critical."

\section{Conclusions}

This review is the first to compile evidence on clinical utility of diagnostic CGS for infant and pediatric patients. CGS uptake, as measured by the number of published reports, has substantially and steadily increased since its commercial debut in 2011. It has been applied in a diverse array of clinical settings and demonstrated ability to determine the molecular basis of disease, even in patients who had previously undergone numerous negative diagnostic investigations.

Information on diagnostic yield alone may not be ideal to determine the value of GS and ES as diagnostic tools. However, downstream outcomes were not consistently defined or reported. While commonly reported information on molecular findings, mode of inheritance, and zygosity are informative for medical geneticists, they do not capture key aspects of CGS relevant for implementation analysis and development of clinical guidelines. Reflecting the dearth of outcomes information, economic analyses have used diagnostic yield as the final health outcome. Lack of standardized outcomes is an obstacle for evaluation of CGS from a health services research perspective, including determination of costeffectiveness. Challenges for generating compelling real world evidence of CGS include determination of best practices for defining, measuring, and reporting patient health outcomes subsequent to sequencing. Future studies should aim to reach consensus among experts regarding which outcomes are important and best practices for measurement and reporting. Focus groups or other forms of structured deliberation among stakeholders are potential means to advance this discussion.

As CGS moves toward standard-of-care, more robust evidence of clinical utility and economic and implementation research on CGS are needed. Consistency in outcome assessment is essential for economic analysis input and as part of the technology translation feedback loop. The power of CGS as a diagnostic tool derives from-and must be evaluated within-a dynamic environment that involves both basic science and application in the clinic.

\section{ELECTRONIC SUPPLEMENTARY MATERIAL}

The online version of this article (https://doi.org/10.1038/s41436018-0024-6) contains supplementary material, which is available to authorized users.

\section{ACKNOWLEDGEMENTS}

The academic department supported this research and was the sole funding source.

\section{FUNDING:}

No funding was obtained for this work.

\section{DISCLOSURE}

The Department of Molecular and Human Genetics at Baylor College of Medicine receives revenue from Baylor Genetics. Dr. Lee is a Consultant for Biomarin and serves on the Scientific Advisory Board of Acer Therapeutics (no income), Rainbow 
Genomics (no income), and the Board of Directors and Scientific Advisory Board of Baylor Genetics (no income). Dr. Lalani is an Assistant Laboratory Director of Baylor Genetics Laboratory. The other authors declare that they have no conflict of interest.

\section{REFERENCES}

1. Manolio TA, Chisholm RL, Ozenberger B, et al. Implementing genomic medicine in the clinic: the future is here. Genet Med. 2013;15:258-67.

2. Chambers DA, Feero W, Khoury MJ. Convergence of implementation science, precision medicine, and the learning health care system: a new model for biomedical research. JAMA. 2016;315:1941-2.

3. Khoury MJ, Gwinn M, Yoon PW, Dowling N, Moore CA, Bradley L. The continuum of translation research in genomic medicine: how can we accelerate the appropriate integration of human genome discoveries into health care and disease prevention? Genet Med. 2007;9:655-74.

4. Daoud H, Luco SM, Li R, et al. Next-generation sequencing for diagnosis of Rare diseases in the neonatal intensive care unit. CMAJ. 2016;188: E254-E260.

5. Meng L, Pammi M, Saronwala A, et al. Use of exome sequencing for infants in intensive care units: ascertainment of severe single-gene disorders and effect on medical management. JAMA Pediatr. 2017;171: e173438-e173438.

6. Willig LK, Petrikin JE, Smith LD, et al. Whole-genome sequencing for identification of Mendelian disorders in critically ill infants: a retrospective analysis of diagnostic and clinical findings. Lancet Respir Med. 2015;3:377-87.

7. Xue Y, Ankala A, Wilcox WR, Hegde MR. Solving the molecular diagnostic testing conundrum for Mendelian disorders in the era of next-generation sequencing: single-gene, gene panel, or exome/genome sequencing. Genet Med. 2015;17:444.

8. Shashi V, McConkie-Rosell A, Rosell B, et al. The utility of the traditional medical genetics diagnostic evaluation in the context of next-generation sequencing for undiagnosed genetic disorders. Genet Med. 2014;16:176-82.

9. Thomas KW. Right test, right time, right patient. Crit Care Med. 2014:42:190-2.

10. Robinson JC. Purchasing medical innovation: the right technology, for the right patient, at the right price. Oakland, CA: University of California Press; 2015.

11. Phillips KA, Ann Sakowski J, Trosman J, Douglas MP, Liang SY, Neumann $P$. The economic value of personalized medicine tests: what we know and what we need to know. Genet Med. 2014;16:251-7.

12. Buchanan J, Wordsworth $S$, Schuh A. Issues surrounding the health economic evaluation of genomic technologies. Pharmacogenomics. 2013;14:1833-47

13. Carlson JJ, Henrikson NB, Veenstra DL, Ramsey SD. Economic analyses of human genetics services: a systematic review. Genet Med. 2005:7:519-23.

14. Berg JS. Genome-scale sequencing in clinical care: establishing molecular diagnoses and measuring value. JAMA. 2014;312:1865-7.

15. Botkin JR, Teutsch SM, Kaye $\mathrm{Cl}$, et al. Outcomes of interest in evidencebased evaluations of genetic tests. Genet Med. 2010;12:228.

16. Tsiplova K, Zur RM, Marshall CR, et al. A microcosting and costconsequence analysis of clinical genomic testing strategies in autism spectrum disorder. Genet Med. 2017;19:1268-75.

17. CADTH. Next generation DNA sequencing: a review of the cost effectiveness and guidelines. Canadian Agency for Drugs and Technologies in Health: 2014.

18. Ng SB, Turner EH, Robertson PD, et al. Targeted capture and massively parallel sequencing of 12 human exomes. Nature. 2009;461:272-6.

19. Choi M, Scholl UI, Ji W, et al. Genetic diagnosis by whole exome capture and massively parallel DNA sequencing. Proc Natl Acad Sci USA. 2009;106:19096-101.

20. Moher D, Liberati A, Tetzlaff J, Altman DG, Group P. Preferred reporting items for systematic reviews and meta-analyses: the PRISMA statement. PLoS Med. 2009;6:e1000097.

21. Ouzzani M, Hammady H, Fedorowicz Z, Elmagarmid A. Rayyan—a web and mobile app for systematic reviews. Syst Rev. 2016;5:210.

22. Husereau D, Drummond M, Petrou S, et al. Consolidated Health Economic Evaluation Reporting Standards (CHEERS)-explanation and elaboration: a report of the ISPOR Health Economic Evaluation
Publication Guidelines Good Reporting Practices Task Force. Value Health. 2013;16:231-50.

23. Burke W, Atkins D, Gwinn M, et al. Genetic test evaluation: information needs of clinicians, policy makers, and the public. Am J Epidemiol. 2002;156:311-8.

24. Aintablian HK, Narayanan V, Belnap N, Ramsey K, Grebe TA. An atypical presentation of ACAD9 deficiency: Diagnosis by whole exome sequencing broadens the phenotypic spectrum and alters treatment approach. Mol Genet Metab Rep. 2017;10:38-44.

25. Andreoletti G, Seaby EG, Dewing JM, et al. AMMECR1: A single point mutation causes developmental delay, midface hypoplasia and elliptocytosis. J Med Genet. 2017;54:269-77.

26. Arboleda VA, Lee $H$, Dorrani $N$, et al. De novo nonsense mutations in KAT6A, a lysine acetyl-transferase gene, cause a syndrome including microcephaly and global developmental delay. Am J Hum Genet. 2015;96:498-506.

27. Ardicli D, Taskiran EZ, Kosukcu C, et al. Neonatal-onset recurrent Guillain-Barré syndrome-like disease: clues for inherited CD59 deficiency. Neuropediatrics. 2017;48:477-81.

28. Bacino CA, Dhar SU, Brunetti-Pierri N, Lee B, Bonnen PE. WDR35 mutation in siblings with Sensenbrenner syndrome: a ciliopathy with variable phenotype. Am J Med Genet A. 2012;158:2917-24.

29. Baertling $F$, Alhaddad B, Seibt A, et al. Neonatal encephalocardiomyopathy caused by mutations in VARS2. Metab Brain Dis. 2017:32:267-70.

30. Balasubramaniam S, Koo M, Lewis B, et al. Leigh-like syndrome due to homoplasmic m.8993t $\mathrm{g}$ variant with hypocitrullinemia and unusual biochemical features suggestive of multiple carboxylase deficiency (MCD). Twin Res Human Genet. 2016;19:531.

31. Balboa-Beltran E, Fernández-Seara MJ, Pérez-Muñuzuri $A$, et al. A novel stop mutation in the vascular endothelial growth factor-C gene (VEGFC) results in Milroy-like disease. J Med Genet. 2014;51:475-8.

32. Bayer DK, Martinez CA, Sorte HS, et al. Vaccine-associated varicella and rubella infections in severe combined immunodeficiency with isolated CD4 lymphocytopenia and mutations in IL7R detected by tandem whole exome sequencing and chromosomal microarray. Clin Exp Immunol. 2014;178:459-69.

33. Bloom JL, Lin C, Imundo L, et al. $\mathrm{H}$ syndrome: 5 new cases from the United States with novel features and responses to therapy. Pediatr Rheumatol Online J. 2017;15:76.

34. Bochner $R$, Samuelov $L$, Sarig $O$, et al. Calpain 12 function revealed through the study of an atypical case of autosomal recessive congenital ichthyosis. J Invest Dermatol. 2017;137:385-93.

35. Boczek NJ, Kruisselbrink T, Cousin MA, et al. Multigenerational pedigree with STAR syndrome: a novel FAM58A variant and expansion of the phenotype. Am J Med Genet A. 2017;173:1328-33.

36. Brion M, De Castro Lopez MJ, Santori $M$, et al. Prospective and retrospective diagnosis of Barth syndrome aided by next-generation sequencing. Am J Clin Pathol. 2016;145:507-13.

37. Bruel AL, Masurel-Paulet $A$, Rivière JB, et al. Autosomal recessive truncating MAB21L1 mutation associated with a syndromic scrotal agenesis. Clin Genet. 2017;91:333-8.

38. Çăglayan AO, Sezer RG, Kaymakçalan $\mathrm{H}$, et al. ALPK3 gene mutation in a patient with congenital cardiomyopathy and dysmorphic features. Cold Spring Harb Mol Case Stud. 2017;3. pii: a001859

39. Caglayan AO, Tuysuz B, Coskun S, et al. A patient with a novel homozygous missense mutation in FTO and concomitant nonsense mutation in CETP. J Hum Genet. 2016;61:395-403.

40. Chen $\mathrm{M}, \mathrm{Wu}$ J, Liang $\mathrm{N}$, et al. Identification of a novel SBF2 frameshift mutation in Charcot-Marie-Tooth disease type 4B2 using whole-exome sequencing. Genomics Proteomics Bioinformatics. 2014;12:221-7.

41. Chen Q, Bao H, Wu H, Zhao S, Huang S, Zhao F. Diagnosis of cobalamin $C$ deficiency with renal abnormality from onset in a Chinese child by next generation sequencing: a case report. Exp Ther Med. 2017;14: 3637-43.

42. Chetta M, Guacci A, Rizzo F, et al. Infantile spasms in early-onset Niemann-Pick disease with a novel compound heterozygous mutations in SMPD1 gene. New Horiz Transl Med. 2015;2:155-8.

43. Chiplunkar S, Bindu PS, Nagappa $M$, et al. Huppke-Brendel syndrome in a seven months old boy with a novel 2-bp deletion in SLC33A1. Metab Brain Dis. 2016;31:1195-8.

44. Chiu ATG, Zhu L, Mok GTK, Leung GKC, Chow CB, Chung BHY. Before and after-nutritional transformation of dysmorphism in a case of Costello syndrome. Eur J Med Genet. 2016;59:573-6. 
45. Choi R, Park HD, Yang M, et al. Novel pathogenic variant (C.580C T) in the CPS1 gene in a newborn with carbamoyl phosphate synthetase 1 deficiency identified by whole exome sequencing. Ann Lab Med. 2017;37:58-62.

46. Choi $\mathrm{R}$, Woo $\mathrm{HI}$, Choe $\mathrm{BH}$, et al. Application of whole exome sequencing to a rare inherited metabolic disease with neurological and gastrointestinal manifestations: a congenital disorder of glycosylation mimicking glycogen storage disease. Clin Chim Acta. 2015;444:50-53.

47. Coe RR, McKinnon ML, Tarailo-Graovac M, et al. A case of splenomegaly in CBL syndrome. Eur J Med Genet. 2017;60:374-9.

48. Das AS, Agamanolis DP, Cohen BH. Use of next-generation sequencing as a diagnostic tool for congenital myasthenic syndrome. Pediatr Neurol. 2014;51:717-20.

49. Demari J, Mroske C, Tang S, Nimeh J, Miller R, Lebel RR. CLTC as a clinically novel gene associated with multiple malformations and developmental delay. Am J Med Genet A. 2016;170:958-66.

50. Dhamija R, Wirrell E, Falcao G, Kirmani S, Wong-Kisiel LC. Novel de novo SCN2A mutation in a child with migrating focal seizures of infancy. Pediatr Neurol. 2016:49:486-8.

51. Dinwiddie DL, Bracken JM, Bass JA, et al. Molecular diagnosis of infantile onset inflammatory bowel disease by exome sequencing. Genomics. 2013;102:442-7.

52. Dionisi-Vici C, Shteyer E, Niceta M, et al. Expanding the molecular diversity and phenotypic spectrum of glycerol 3-phosphate dehydrogenase 1 deficiency. J Inherit Metab Dis. 2016;39:689-95.

53. Dyment DA, Sell E, Vanstone MR, et al. Evidence for clinical, genetic and biochemical variability in spinal muscular atrophy with progressive myoclonic epilepsy. Clin Genet. 2014;86:558-63.

54. Edvardson S, Yi JK, Jalas C, et al. Deficiency of the alkaline ceramidase ACER3 manifests in early childhood by progressive leukodystrophy. J Med Genet. 2016;53:389-96.

55. Eskandrani A, AlHashem A, Ali ES, et al. Recessive AFG3L2 mutation causes progressive microcephaly, early onset seizures, spasticity, and basal ganglia involvement. Pediatr Neurol. 2017;71:24-28.

56. Fadus MC, Rush ET, Lettieri CK. Syndrome of progressive bone marrow failure and pancreatic insufficiency remains cryptic despite whole exome sequencing: variant of Shwachman-Diamond syndrome or new condition? Clin Case Rep. 2017;5:748-52.

57. Fraser $J$, Vanderver $A$, et al. Thiamine pyrophosphokinase deficiency causes a Leigh disease like phenotype in a sibling pair: identification through whole exome sequencing and management strategies. Mol Genet Metab Rep. 2014;1:66-70.

58. Gallagher JL, Verbsky J, Hintermeyer $M$, et al. X-linked hyper IgM syndrome presenting as pulmonary alveolar proteinosis. Ann Allergy Asthma Immunol. 2015:115:A101.

59. Garg N, Bademci G, Foster J, Siklar Z, Berberoglu M, Tekin M. MORFAN syndrome: an infantile hypoinsulinemic hypoketotic hypoglycemia due to an AKT2 mutation. J Pediatr. 2015;167:489-91.

60. Gerald B, Ramsey K, Belnap N, et al. Neonatal epileptic encephalopathy caused by de novo GNAO1 mutation misdiagnosed as atypical Rett syndrome: cautions in interpretation of genomic test results. Seminars in Pediatr Neurol. 2017; advance online publication August 16, 2017. https://doi.org/10.1016/j.spen.2017.08.008.

61. Goldstein JHR, Tim-aroon T, Shieh J, et al. Novel SMC1A frameshift mutations in children with developmental delay and epilepsy. Eur J Med Genet. 2015;58:562-8.

62. Goodwin G, Hawley PP, Miller DT. A case of HDR syndrome and ichthyosis: dual diagnosis by whole-genome sequencing of novel mutations in GATA3 and STS genes. J Clin Endocrinol Metab. 2016;101:837-40.

63. Guella I, Huh L, McKenzie MB, et al. De novo FGF12 mutation in 2 patients with neonatal-onset epilepsy. Neurol Genet. 2016;2:e120.

64. Haberman Y, Di Segni A, Loberman-Nachum N, et al. Congenital sucraseisomaltase deficiency: a novel compound heterozygous mutation causing aberrant protein localization. J Pediatr Gastroenterol Nutr. 2017;64:770-6.

65. Harel T, Posey JE, Graham BH, et al. Atypical presentation of moyamoya disease in an infant with a de novo RNF213 variant. Am J Med Genet A. 2015;167:2742-7.

66. Hasosah MY, Iskandarani Al, Shawli Al, Alsahafi AF, Sukkar GA, Qurashi MA. Neuroblastoma amplified sequence gene mutation: a rare cause of recurrent liver failure in children. Saudi J Gastroenterol. 2017;23:206-8.
67. He X, Zou R, Zhang B, You Y, Yang Y, Tian X. Whole Wiskott-Aldrich syndrome protein gene deletion identified by high throughput sequencing. Mol Med Rep. 2017;16:6526-31.

68. Hegde AU, Sanghvi KP, Karnavat PK, Jalan AB. BRCA1-associated ataxia telangiectasia mutated activation-1 mutation: an addition to the early infantile epileptic encephalopathy panel. J Clin Neonatol. 2017;6:200-4.

69. Hildreth A, Wigby K, Chowdhury S, et al. Rapid whole-genome sequencing identifies a novel homozygous NPC1 variant associated with Niemann-Pick type C1 disease in a 7-week-old male with cholestasis. Cold Spring Harb Mol Case Stud. 2017;3:a001966.

70. Hirabayashi S, Saitsu H, Matsumoto N. Distinct but milder phenotypes with choreiform movements in siblings with compound heterozygous mutations in the transcription preinitiation mediator complex subunit 17 (MED17). Brain Dev. 2016;38:118-23.

71. Holzerova E, Danhauser K, Haack TB, et al. Human thioredoxin 2 deficiency impairs mitochondrial redox homeostasis and causes earlyonset neurodegeneration. Brain. 2016;139:346-54.

72. Ichimura $T$, Yoshida $K$, Okuno $Y$, et al. Diagnostic challenge of Diamond-Blackfan anemia in mothers and children by whole-exome sequencing. Int J Hematol. 2017;105:515-20.

73. Ikeda $T$, Nakahara $A$, Nagano $R$, et al. TBCD may be a causal gene in progressive neurodegenerative encephalopathy with atypical infantile spinal muscular atrophy. J Hum Genet. 2017;62:473-80.

74. Inui T, Kobayashi S, Ashikari $Y$, et al. Two cases of early-onset myoclonic seizures with continuous parietal delta activity caused by EEF1A2 mutations. Brain Dev. 2016;38:520-4.

75. Jehee FS, de Oliveira VT, Gurgel-Giannetti J, et al. Dual molecular diagnosis contributes to atypical Prader-Willi phenotype in monozygotic twins. Am J Med Genet A. 2017;173:2451-5.

76. Jezela-Stanek A, Ciara E, Piekutowska-Abramczuk D, et al. Congenital disorder of glycosylphosphatidylinositol (GPI)-anchor biosynthesis-the phenotype of two patients with novel mutations in the PIGN and PGAP2 genes. Eur J Paediatr Neurol. 2016;20:462-73.

77. Johannsen J, Hempel $M$, Diehl T, Haack TB, Denecke J. Exome sequencing is a valuable approach in critically ill patients with suspected monogenic disease: diagnosis of X-linked centronuclear myopathy in preterm twins. Pediatr Neonatol. 2017;58:458-9.

78. Joshi C, Kolbe DL, Mansilla MA, Mason S, Smith RJH, Campbell CA. Ketogenic diet-a novel treatment for early epileptic encephalopathy due to PIGA deficiency. Brain Dev. 2016;38:848-51.

79. Kansal R, Li X, Shen J, et al. An infant with MLH3 variants, FOXG1duplication and multiple, benign cranial and spinal tumors: a clinical exome sequencing study. Genes Chromosomes Cancer. 2016;55:131-42.

80. Keller MD, Ganesh J, Heltzer $M$, et al. Severe combined immunodeficiency resulting from mutations in MTHFD1. Pediatrics. 2013;131:e629-e634.

81. Kettwig M, Elpeleg O, Wegener $E$, et al. Compound heterozygous variants in PGAP1 causing severe psychomotor retardation, brain atrophy, recurrent apneas and delayed myelination: a case report and literature review. BMC Neurol. 2016;16:74.

82. Khromykh A, Solomon BD, Bodian DL, et al. Diagnosis of D-bifunctional protein deficiency through whole-genome sequencing: implications for cost-effective care. Mol Syndromol. 2015;6:141-6.

83. Kimizu T, Takahashi Y, Oboshi T, et al. A case of early onset epileptic encephalopathy with de novo mutation in SLC35A2: clinical features and treatment for epilepsy. Brain Dev. 2017;39:256-60.

84. Kohrogi $K$, Imagawa $E$, Muto $Y$, et al. Biotin-responsive basal ganglia disease: a case diagnosed by whole exome sequencing. J Hum Genet. 2015;60:381-5.

85. Kuloglu Z, Kansu A, Serwas N, et al. Inflammatory bowel disease-like phenotype in a young girl with prolidase deficiency: a new spectrum of clinical manifestation. Genet Couns. 2015;26:205-11.

86. Kvarnung M, Taylan F, Nilsson D, et al. Mutations in FLVCR2 associated with Fowler syndrome and survival beyond infancy. Clin Genet. 2016;89:99-103.

87. Lange L, Pagnamenta AT, Lise $S$, et al. A de novo frameshift in HNRNPK causing a Kabuki-like syndrome with nodular heterotopia. Clin Genet. 2016;90:258-62.

88. Law CY, Chang STL, Cho SY, et al. Clinical whole-exome sequencing reveals a novel missense pathogenic variant of GNAO1 in a patient with infantile-onset epilepsy. Clin Chim Acta. 2015;451:292-6. 
89. Leduc MS, Chao HT, Qu C, et al. Clinical and molecular characterization of de novo loss of function variants in HNRNPU. Am J Med Genet A. 2017;173:2680-9.

90. Lee JJY, van Karnebeek CDM, Drögemoller B, et al. Further validation of the SIGMAR1 c.151+1G T mutation as cause of distal hereditary motor neuropathy. Child Neurol Open. 2017;3:2329048X16669912.

91. Lee JS, Lee S, Lim BC, et al. Alpha-thalassemia X-linked intellectual disability syndrome identified by whole exome sequencing in two boys with white matter changes and developmental retardation. Gene. 2015;569:318-22.

92. Lee JS, Yoo Y, Lim BC, et al. GM3 synthase deficiency due to ST3GAL5 variants in two Korean female siblings: Masquerading as Rett syndromelike phenotype. Am J Med Genet A. 2016;170:2200-5.

93. Li N, Li J, Ding Y, et al. Novel mutations in the CYP11B2 gene causing aldosterone synthase deficiency. Mol Med Rep. 2016;13:3127-32.

94. Lim BC, Yoo SK, Lee S, et al. Hoyeraal-Hreidarsson syndrome with a DKC1 mutation identified by whole-exome sequencing. Gene. 2014;546:425-9.

95. Lines MA, Ito $Y$, Kernohan KD, et al. Yunis-Varón syndrome caused by biallelic VAC 14 mutations. Eur J Hum Genet. 2017;25:1049-54.

96. Makrythanasis P, Temtamy S, Aglan MS, Otaify GA, Hamamy $H$, Antonarakis SE. A novel homozygous mutation in FGFR3 causes tall stature, severe lateral tibial deviation, scoliosis, hearing impairment, camptodactyly, and arachnodactyly. Hum Mutat. 2014;35:959-63.

97. Miyamichi D, Asahina M, Nakajima J, et al. Novel HPS6 mutations identified by whole-exome sequencing in two Japanese sisters with suspected ocular albinism. J Hum Genet. 2016;61:839-42.

98. Mohammad S, Wolfe LA, Stöbe P, et al. Infantile cirrhosis, growth impairment, and neurodevelopmental anomalies associated with deficiency of PPP1R15B. J Pediatr. 2016;179:144-e142.

99. Mroske C, Rasmussen K, Shinde DN, et al. Germline activating MTOR mutation arising through gonadal mosaicism in two brothers with megalencephaly and neurodevelopmental abnormalities. BMC Med Genet. 2015;16:102.

100. Murray $C R$, Abel SN, McClure MB, et al. Novel causative variants in DYRK1A, KARS, and KAT6A associated with intellectual disability and additional phenotypic features. J Pediatr Genet. 2017;6:77-83.

101. Nafisinia M, Riley LG, Gold WA, et al. Compound heterozygous mutations in glycyl-tRNA synthetase (GARS) cause mitochondrial respiratory chain dysfunction. PLOS ONE. 2017;12:e0178125.

102. Nakamura $Y$, Togawa $Y$, Okuno $Y$, et al. SZT2 mutations cause a discernible disorder with developmental delay and dysmorphic corpus callosum. No To Hattatsu. 2017;49:S289.

103. Naseer Ml, Sogaty S, Rasool M, et al. Microcephaly-capillary malformation syndrome: brothers with a homozygous STAMBP mutation, uncovered by exome sequencing. Am J Med Genet $A$. 2016;170:3018-22.

104. Ohashi T, Akasaka N, Kobayashi $Y$, et al. Infantile epileptic encephalopathy with a hyperkinetic movement disorder and hand stereotypies associated with a novel SCN1A mutation. Epileptic Disord. 2014;16:208-12.

105. Ozkinay F, Atik T, Isik E, et al. A further family of Stromme syndrome carrying CENPF mutation. Am J Med Genet A. 2017;173:1668-72.

106. Palagano $E$, Slatter MA, Uva $P$, et al. Hematopoietic stem cell transplantation corrects osteopetrosis in a child carrying a novel homozygous mutation in the FERMT3 gene. Bone. 2017;97:126-9.

107. Per H, Canpolat M, Bayram AK, et al. Clinical, electrodiagnostic, and genetic features of Tangier disease in an adolescent girl with presentation of peripheral neuropathy. Neuropediatrics. 2015;46:420-3.

108. Peragallo JH, Keller S, van der Knaap MS, Soares BP, Shankar SP. Retinopathy and optic atrophy: expanding the phenotypic spectrum of pathogenic variants in the AARS2 gene. Ophthalmic Genet. 2018;39:99-102.

109. Piekutowska-Abramczuk D, Mierzewska H, Bekiesinska-Figatowska M, et al. Bilateral striatal necrosis caused by ADAR mutations in two siblings with dystonia and freckles-like skin changes that should be differentiated from Leigh syndrome. Folia Neuropathol. 2016;54:405-9.

110. Pierson TM, Adams D, Bonn F, et al. Whole-exome sequencing identifies homozygous AFG3L2 mutations in a spastic ataxia-neuropathy syndrome linked to mitochondrial m-AAA proteases. PLoS Genet. 2011;7:e1002325.

111. Pinto AM, Bianciardi L, Mencarelli MA, et al. Exome sequencing analysis in a pair of monozygotic twins re-evaluates the genetics behind their intellectual disability and reveals a CHD2 mutation. Brain Dev. 2016;38:590-6.

112. Pizzino A, Pierson TM, Guo $Y$, et al. TUBB4A de novo mutations cause isolated hypomyelination. Neurology. 2014;83:898-902.

113. Popp B, Trollmann R, Büttner C, et al. Do the exome: A case of WilliamsBeuren syndrome with severe epilepsy due to a truncating de novo variant in GABRA1. Eur J Med Genet. 2016;59:549-53.

114. Porntaveetus T, Srichomthong C, Suphapeetiporn K, Shotelersuk V. Monoallelic FGFR3 and biallelic ALPL mutations in a Thai girl with hypochondroplasia and hypophosphatasia. Am J Med Genet A. 2017;173:2747-52.

115. Powis Z, Hart A, Cherny S, et al. Clinical diagnostic exome evaluation for an infant with a lethal disorder: Genetic diagnosis of TARP syndrome and expansion of the phenotype in a patient with a newly reported RBM10 alteration. BMC Med Genet. 2017;18:60.

116. Priest JR, Ceresnak SR, Dewey FE, et al. Molecular diagnosis of long QT syndrome at 10 days of life by rapid whole genome sequencing. Heart Rhythm. 2014;11:1707-13.

117. Prontera P, Micale L, Verrotti A, Napolioni V, Stangoni G, Merla G. A new homozygous IGF1R variant defines a clinically recognizable incomplete dominant form of SHORT syndrome. Hum Mutat. 2015;36:1043-7.

118. Punwani $D$, Wang $H, C$ han $A Y$, et al. Combined immunodeficiency due to MALT1 mutations, treated by hematopoietic cell transplantation. J Clin Immunol. 2015;35:135-46.

119. Purnell SM, Bleyl SB, Bonkowsky JL. Clinical exome sequencing identifies a novel TUBB4A mutation in a child with static hypomyelinating leukodystrophy. Pediatr Neurol. 2014;50:608-11.

120. Ramakrishnan KA, Pengelly RJ, Gao Y, et al. Precision molecular diagnosis defines specific therapy in combined immunodeficiency with megaloblastic anemia secondary to MTHFD1 deficiency. J Allergy Clin Immunol Pract. 2016;4:1160-.e1110.

121. Renkema GH, Visser G, Baertling F, et al. Mutated PET117 causes complex IV deficiency and is associated with neurodevelopmental regression and medulla oblongata lesions. Hum Genet. 2017;136:759-69.

122. Reuter MS, Sass JO, Leis T, et al. HIBCH deficiency in a patient with phenotypic characteristics of mitochondrial disorders. Am J Med Genet A. 2014;164:3162-9.

123. Rios J, Stein E, Shendure J, Hobbs HH, Cohen JC. Identification by whole-genome resequencing of gene defect responsible for severe hypercholesterolemia. Hum Mol Genet. 2010;19:4313-8.

124. Sangsin A, Srichomthong C, Pongpanich M, Suphapeetiporn K, Shotelersuk $V$. Whole-exome sequencing reveals a novel COL2A1 mutation in a patient with spondyloepiphyseal dysplasia congenita. Genet Mol Res. 2016;15:15017624.

125. Santra S, Cameron JM, Shyr C, et al. Cytosolic phosphoenolpyruvate carboxykinase deficiency presenting with acute liver failure following gastroenteritis. Mol Genet Metab. 2016;118:21-27.

126. Seidahmed MZ, Salih MA, Abdulbasit OB, et al. Hyperekplexia, microcephaly and simplified gyral pattern caused by novel ASNS mutations, case report. BMC Neurol. 2016;16:105.

127. Shimojima K, Narita A, Maegaki Y, Saito A, Furukawa T, Yamamoto T. Whole-exome sequencing identifies a de novo TUBA1A mutation in a patient with sporadic malformations of cortical development: a case report. BMC Res Notes. 2014;7:465.

128. Shiota $M$, Yang $X$, Kubokawa $M$, et al. Somatic mosaicism for a NRAS mutation associates with disparate clinical features in RAS-associated leukoproliferative disease: a report of two cases. J Clin Immunol. 2015;35:454-8.

129. Stanik J, Skopkova M, Brennerova K, et al. Congenital hyperinsulinism and glycogenosis-like phenotype due to a novel HNF4A mutation. Diabetes Res Clin Pract. 2017;126:144-50.

130. Stiles AR, Ferdinandusse $S$, et al. Successful diagnosis of $H I B C H$ deficiency from exome sequencing and positive retrospective analysis of newborn screening cards in two siblings presenting with Leigh's disease. Mol Genet Metab. 2015;115:161-7.

131. Subramanian VS, Constantinescu AR, Benke PJ, Said HM. Mutations in SLC5A6 associated with brain, immune, bone, and intestinal dysfunction in a young child. Hum Genet. 2017;136:253-61.

132. Takeda $R$, Takagi $M$, Shinohara $H$, et al. Novel compound heterozygous mutations identified by whole exome sequencing in a Japanese patient with geroderma osteodysplastica. Eur J Med Genet. 2017;60:635-8. 
133. Tamura S, Higuchi K, Tamaki M, et al. Novel compound heterozygous DNA ligase IV mutations in an adolescent with a slowly-progressing radiosensitive-severe combined immunodeficiency. Clin Immunol. 2015;160:255-60.

134. Thiffault I, Saunders C, Jenkins J, et al. A patient with polymerase E1 deficiency (POLE1): clinical features and overlap with DNA breakage/ instability syndromes. BMC Med Genet. 2015;16:31.

135. Topa A, Tulinius M, Oldfors A, Hedberg-Oldfors C. Novel myopathy in a newborn with Shwachman-Diamond syndrome and review of neonatal presentation. Am J Med Genet A. 2016;170:1155-64.

136. Tosur M, Jeha GS. A novel intragenic SLC16A1 mutation associated with congenital hyperinsulinism. Glob Pediatr Health. 2017; 4: 2333794X17703462

137. Tsabari R, Daum H, Kerem E, Fellig Y, Dor T. Congenital myopathy due to myosin heavy chain 2 mutation presenting as chronic aspiration pneumonia in infancy. Neuromuscul Disord. 2017;27:947-50.

138. Vanderver A, Simons C, Schmidt JL, et al. Identification of a novel de novo p.Phe932lle KCNT1 mutation in a patient with leukoencephalopathy and severe epilepsy. Pediatr Neurol. 2014;50:112-4.

139. Vanstone JR, Smith AM, McBride S, et al. DNM1L-related mitochondrial fission defect presenting as refractory epilepsy. Eur J Hum Genet. 2016;24:1084-8

140. Varma $H$, Faust $P L$, Iglesias $A D$, et al. Whole exome sequencing identifies a homozygous POLG2 missense variant in an infant with fulminant hepatic failure and mitochondrial DNA depletion. Eur J Med Genet. 2016;59:540-5.

141. Villeneuve N, Abidi A, Cacciagli P, et al. Heterogeneity of FHF1 related phenotype: novel case with early onset severe attacks of apnea, partial mitochondrial respiratory chain complex II deficiency, neonatal onset seizures without neurodegeneration. Eur J Paediatr Neurol. 2017;21:783-6.

142. Wang $X$, Zhou K, Hua Y, Li Y. Approaching the facts between genetic mutation and clinical practice of hypertrophic cardiomyopathy: a case report with RAF1 770C T mutant. Medicine (Baltimore). 2016;95: e4815.

143. Wasserman $H$, Hufnagel RB, Miraldi Utz V, et al. Bilateral cataracts in a 6-yr-old with new onset diabetes: a novel presentation of a known INS gene mutation. Pediatr Diabetes. 2016;17:535-9.

144. Wassner AJ, Cohen LE, Hechter E, Dauber A. Isolated central hypothyroidism in young siblings as a manifestation of PROP1 deficiency: clinical impact of whole exome sequencing. Horm Res Paediatr. 2013;79:379-86.

145. Wentworth K, Hsing A, Urrutia A, et al. A novel T55A variant of Gs $\alpha$ associated with impaired CAMP production, bone fragility, and osteolysis. Case Rep Endocrinol. 2016;2016:2691385.

146. Wilbur C, Buerki SE, Guella I, et al. An infant with epilepsy and recurrent hemiplegia due to compound heterozygous variants in ATP1A2. Pediatr Neurol. 2017;75:87-90.

147. Williams HJ, Hurst JR, Ocaka L, et al. The use of whole-exome sequencing to disentangle complex phenotypes. Eur J Hum Genet. 2016;24:298-301.

148. Xia F, Bainbridge MN, Tan TY, et al. De novo truncating mutations in AHDC 1 in individuals with syndromic expressive language delay, hypotonia, and sleep apnea. Am J Hum Genet. 2014;94:784-9.

149. Yamamoto T, Endo W, Ohnishi $H$, et al. The first report of Japanese patients with asparagine synthetase deficiency. Brain Dev. 2017;39:236-42.

150. Yourshaw M, Solorzano-Vargas RS, Pickett LA, et al. Exome sequencing finds a novel PCSK1 mutation in a child with generalized malabsorptive diarrhea and diabetes insipidus. I Pediatr Gastroenterol Nutr. 2013;57:759-67.

151. Yu HC, Geiger EA, Medne L, Zackai EH, Shaikh TH. An individual with blepharophimosis-ptosis-epicanthus inversus syndrome (BPES) and additional features expands the phenotype associated with mutations in KAT6B. Am J Med Genet A. 2014;164:950-7.

152. Zrhidri A, Jaouad IC, Lyahyai J, et al. Identification of two novel SH3PXD2B gene mutations in Frank-Ter Haar syndrome by exome sequencing: case report and review of the literature. Gene. 2017;628:190-3.

153. Joshi C, Kolbe DL, Mansilla MA, Mason SO, Smith RJ, Campbell CA. Reducing the cost of the diagnostic odyssey in early onset epileptic encephalopathies. Biomed Res Int. 2016;2016:6421039.
154. Bick D, Fraser PC, Gutzeit MF, et al. Successful application of whole genome sequencing in a medical genetics clinic. J Pediatr Genet. 2017;6:61-76.

155. Bowling KM, Thompson ML, Amaral MD, et al. Genomic diagnosis for children with intellectual disability and/or developmental delay. Genome Med. 2017;9:43.

156. Farwell KD, Shahmirzadi L, El-Khechen D, et al. Enhanced utility of family-centered diagnostic exome sequencing with inheritance modelbased analysis: results from 500 unselected families with undiagnosed genetic conditions. Genet Med. 2015;17:578-86.

157. Gauthier-Vasserot A, Thauvin-Robinet C, Bruel A-L, et al. Application of whole-exome sequencing to unravel the molecular basis of undiagnosed syndromic congenital neutropenia with intellectual disability. Am J Med Genet A. 2017;173:62-71.

158. Helbig KL, Farwell Hagman KD, Shinde DN, et al. Diagnostic exome sequencing provides a molecular diagnosis for a significant proportion of patients with epilepsy. Genet Med. 2016;18:898-905.

159. Iglesias A, Anyane-Yeboa K, Wynn J, et al. The usefulness of wholeexome sequencing in routine clinical practice. Genet Med. 2014;16:922-31.

160. Lazaridis KN, Schahl KA, Cousin MA, et al. Outcome of whole exome sequencing for diagnostic odyssey cases of an individualized medicine clinic: the Mayo Clinic experience. Mayo Clin Proc. 2016;91:297-307.

161. Lee $H$, Deignan JL, Dorrani $N$, et al. Clinical exome sequencing for genetic identification of rare Mendelian disorders. JAMA. 2014;312:1880-7.

162. Lionel AC, Costain G, Monfared N, et al. Improved diagnostic yield compared with targeted gene sequencing panels suggests a role for whole-genome sequencing as a first-tier genetic test. Genet Med 2018;4:435-443; advance online publication August 3, 2017. https:// doi.org/10.1038/gim.2017.119

163. Nambot $S$, Thevenon J, Kuentz $P$, et al. Clinical whole-exome sequencing for the diagnosis of rare disorders with congenital anomalies and/or intellectual disability: substantial interest of prospective annual reanalysis. Genet Med advance online publication November 2, 2017. https://doi.org/10.1038/gim.2017

164. Need AC, Shashi V, Hitomi $Y$, et al. Clinical application of exome sequencing in undiagnosed genetic conditions. J Med Genet. 2012;49:353-61.

165. Nolan D, Carlson M. Whole exome sequencing in pediatric neurology patients: clinical implications and estimated cost analysis. J Child Neurol. 2016;31:887-94.

166. Ream MA, Mikati MA. Clinical utility of genetic testing in pediatric drugresistant epilepsy: a pilot study. Epilepsy Behav. 2014;37:241-8.

167. Romasko EJ, Devkota B, Biswas S, et al. Utility and limitations of exome sequencing in the molecular diagnosis of pediatric inherited platelet disorders. Am J Hematol. 2018;93:8-16; advance online publication October 20, 2017. https://doi.org/10.1002/ajh.24917

168. Rump P, Jazayeri O, Van Dijk-Bos KK, et al. Whole-exome sequencing is a powerful approach for establishing the etiological diagnosis in patients with intellectual disability and microcephaly. BMC Med Genom. 2016:9:7.

169. Sawyer SL, Hartley T, Dyment DA, et al. Utility of whole-exome sequencing for those near the end of the diagnostic odyssey: time to address gaps in care. Clin Genet. 2015;89:275-84.

170. Shamriz O, Shaag A, Yaacov B, et al. The use of whole exome sequencing for the diagnosis of autosomal recessive malignant infantile osteopetrosis. Clin Genet. 2017;92:80-85.

171. Shashi V, McConkie-Rosell A, Schoch K, et al. Practical considerations in the clinical application of whole-exome sequencing. Clin Genet. 2016;89:173-81.

172. Soden SE, Saunders CJ, Willig LK, et al. Effectiveness of exome and genome sequencing guided by acuity of illness for diagnosis of neurodevelopmental disorders. Sci Trans/ Med. 2014;6:265ra168.

173. Srivastava S, Cohen JS, Vernon $H$, et al. Clinical whole exome sequencing in child neurology practice. Ann Neurol. 2014;76:473-83.

174. Stark Z, Tan TY, Chong B, et al. A prospective evaluation of wholeexome sequencing as a first-tier molecular test in infants with suspected monogenic disorders. Genet Med. 2016;18:1090-6.

175. Stavropoulos DJ, Merico D, Jobling R, et al. Whole genome sequencing expands diagnostic utility and improves clinical management in pediatric medicine. NPJ Genom Med. 2016;1:15012. 


\section{SYSTEMATIC REVIEW}

176. Takeichi T, Nanda A et al. Impact of next generation sequencing on diagnostics in a genetic skin disease clinic. Exp Dermatol. 2013;22:825-31.

177. Tammimies K, Marshall CR, Walker S, et al. Molecular diagnostic yield of chromosomal microarray analysis and whole-exome sequencing in children with autism spectrum disorder. JAMA. 2015;314:895-903.

178. Tarailo-Graovac M, Shyr C, Ross CJ, et al. Exome sequencing and the management of neurometabolic disorders. $N$ Engl J Med. 2016;374:2246-55.

179. Taylor RW, Pyle A, Griffin H, et al. Use of whole-exome sequencing to determine the genetic basis of multiple mitochondrial respiratory chain complex deficiencies. JAMA. 2014;312:68-77.

180. Thevenon J, Duffourd $Y$, Masurel-Paulet A, et al. Diagnostic odyssey in severe neurodevelopmental disorders: toward clinical whole-exome sequencing as a first-line diagnostic test. Clin Genet. 2016;89: 700-7.

181. Trujillano D, Bertoli-Avella AM, Kumar Kandaswamy K, et al. Clinical exome sequencing: results from 2819 samples reflecting 1000 families. Eur J Hum Genet. 2017;25:176-82.

182. Valencia CA, Husami A, Holle J, et al. Clinical impact and costeffectiveness of whole exome sequencing as a diagnostic tool: a pediatric center's experience. Front Pediatr. 2015;3:67.

183. Vissers LE, van Nimwegen KJ, Schieving JH, et al. A clinical utility study of exome sequencing versus conventional genetic testing in pediatric neurology. Genet Med. 2017;19:1055-63.

184. Wortmann SB, Koolen DA, Smeitink JA, van den Heuvel L, Rodenburg RJ. Whole exome sequencing of suspected mitochondrial patients in clinical practice. J Inherit Metab Dis. 2015:38:437-43.
SMITH et al | Clinical Application of GS and ES as a Diagnostic Tool for Pediatric...

185. Yang Y, Muzny DM, Reid JG, et al. Clinical whole-exome sequencing for the diagnosis of mendelian disorders. N Engl J Med. 2013;369: 1502-11.

186. Yang $Y$, Muzny DM, Xia F, et al. Molecular findings among patients referred for clinical whole-exome sequencing. JAMA. 2014;312: 1870-9.

187. Yavarna T, Al-Dewik N, Al-Mureikhi M, et al. High diagnostic yield of clinical exome sequencing in Middle Eastern patients with Mendelian disorders. Hum Genet. 2015;134:967-80.

188. Zhang J, Barbaro P, Guo Y, et al. Utility of next-generation sequencing technologies for the efficient genetic resolution of haematological disorders. Clin Genet. 2016:89:163-72.

189. Monroe GR, Frederix GW, Savelberg SM, et al. Effectiveness of whole-exome sequencing and costs of the traditional diagnostic trajectory in children with intellectual disability. Genet Med. 2016;18: 949-56.

190. Stark Z, Schofield D, Alam K, et al. Prospective comparison of the costeffectiveness of clinical whole-exome sequencing with that of usual care overwhelmingly supports early use and reimbursement. Genet Med. 2017; 19:867-74

191. Tan TY, Dillon OJ, Stark $Z$, et al. Diagnostic impact and costeffectiveness of whole-exome sequencing for ambulant children with suspected monogenic conditions. JAMA Pediatr. 2017;171:855-62.

192. Richards S, Aziz N, Bale S, et al. Standards and guidelines for the interpretation of sequence variants: a joint consensus recommendation of the American College of Medical Genetics and Genomics and the Association for Molecular Pathology. Genet Med. 2015;17:405-23. 